\title{
Androgen-replacement therapy depresses the ex vivo production of inflammatory cytokines by circulating antigen-presenting cells in aging type-2 diabetic men with partial androgen deficiency
}

\author{
J J Corrales, M Almeida ${ }^{1}$, R Burgo, M T Mories, J M Miralles \\ and A Orfao ${ }^{1}$ \\ Servicio de Endocrinología, Hospital Universitario de Salamanca, Paseo de San Vicente 58-182, 37007 Salamanca, Spain \\ ${ }^{1}$ Servicio General de Citometría and Servicio de Endocrinología, Departamento de Medicina, Universidad de Salamanca, Spain \\ (Requests for offprints should be addressed to J J Corrales; Email: corrales@usal.es)
}

\begin{abstract}
Androgens are considered to have immunomodulatory effects but their cellular mechanisms of action remain largely unknown. In the present study we prospectively analyzed the serial effects of androgen-replacement therapy on both the distribution of peripheral blood lymphocytes, monocytes and dendritic cells as well as on the production of interleukin (IL)-1 $\beta$, IL-6 and tumor necrosis factor $\alpha(\mathrm{TNF} \alpha)$ inflammatory cytokines by circulating monocytes and CD33 myeloid, CD16 and plasmacytoid dendritic cell subsets, the most potent antigen-presenting cells (APCs) in type-2 diabetic men with partial androgen deficiency. Analyses were performed before therapy and at 1, 3, 6 and 12 months after treatment with $150 \mathrm{mg}$ testosterone enanthate every 2 weeks in a group of 13 type- 2 diabetic men. Our results show for the first time that testosterone-replacement therapy is associated with a reduction or complete abrogation
\end{abstract}

of spontaneous ex vivo production of IL-1 $\beta$, IL-6 and TNF $\alpha$ by APCs. Meanwhile, the in vitro production of inflammatory cytokines by these cells after stimulation with lipopolysaccharide plus recombinant human interferon- $\gamma$ remained unchanged, suggesting that APCs preserve their constitutive machinery to produce inflammatory cytokines under androgen treatment. These results confirm and extend previous observations about the anti-inflammatory effects of androgen therapy on APCs in a new, previously unexplored model of androgen deficiency; namely, aging type-2 diabetic men. A decreased production of inflammatory cytokines by APCs might have important consequences for sex differences in susceptibility to autoimmune diseases, inflammatory response to injury and atheromatosis.

Journal of Endocrinology (2006) 189, 595-604

\section{Introduction}

Aging in men is associated with a progressive decrease in serum testosterone levels and an increase in the prevalence of hypogonadism (Harman et al. 2001, Feldman et al. 2002). Although the age-related decrease in testosterone levels is independent of health status (Harman et al. 2001), in diseases such as diabetes mellitus androgen deficiency could be exacerbated since lower testosterone values have been reported in older type-2 diabetic men than in age-matched non-diabetic individuals (Barrett-Connor et al. 1990, Anderson et al. 1994). The partial androgen deficiency detected in aging men has been related to the development of multiple symptoms and signs, and it has been shown that androgen-replacement therapy may induce improvements of lean body mass (Tenover 1992, Snyder et al. 1999, Kenny et al. 2001), bone mineral density (Kenny et al. 2001), libido (Hajjar et al. 1997), sexual function (Kunelius et al. 2002), grip strength (Sih et al. 1997) and spatial cognition (Janowski et al. 1994), together with a decrease in body fat mass (Snyder et al. 1999, Kenny et al. 2001). Nevertheless, present information about the benefits and risks of testosterone replacement is limited and there is consensus about the need for further studies in which the effects of androgen replacement in aging males can be evaluated (American Society for Reproductive Medicine 2004, Snyder 2004).

In line with this, little is known about the cellular effects of androgen-replacement therapy on the immune response in men (Jacobson \& Ansari 2004). Further insight into this field may contribute to the understanding of the mechanisms involved in the beneficial effects of androgens on the immune system (Malkin et al. 2003, Cutolo et al. 2004) and their protective effect against the development of autoinmune diseases (Bizzarro et al. 1987, Fitzpatrick et al. 1991, Bebo et al. 1998, Gylling et al. 2003). In fact, 
Table 1 Clinical features of controls and type-2 diabetic men

\begin{tabular}{|c|c|c|c|}
\hline & $\begin{array}{l}\text { Controls } \\
(n=8)\end{array}$ & $\begin{array}{l}\text { Type-2 diabetic men } \\
(n=13)\end{array}$ & $P$ value \\
\hline \multicolumn{4}{|l|}{ Parameter } \\
\hline Age (years) & $64 \pm 3$ & $64 \pm 6$ & ns \\
\hline Weight $(\mathrm{kg})$ & $73 \cdot 2 \pm 12 \cdot 5$ & $77 \cdot 6 \pm 14$ & ns \\
\hline Body mass index $\left(\mathrm{kg} / \mathrm{m}^{2}\right)$ & $26 \cdot 8 \pm 1 \cdot 2$ & $27 \cdot 3 \pm 3 \cdot 8$ & ns \\
\hline Fasting plasma glucose (mg/dl) & $85 \pm 3$ & $153 \pm 11$ & $0 \cdot 001^{*}$ \\
\hline $\mathrm{HbA1c}(\%)$ & NM & $6 \cdot 9 \pm 0 \cdot 4$ & \\
\hline Fasting plasma insulin $(\mu \mathrm{lU} / \mathrm{ml})$ & $12 \cdot 9 \pm 3 \cdot 7$ & $15 \cdot 4 \pm 3 \cdot 4$ & ns \\
\hline Fasting plasma C-peptide (pmol/ml) & $0.95 \pm 0.2$ & $0 \cdot 5 \pm 0 \cdot 1$ & $0 \cdot 04^{*}$ \\
\hline Total testosterone $(\mathrm{ng} / \mathrm{ml})$ & $5 \cdot 2 \pm 0 \cdot 6$ & $3 \cdot 9 \pm 0 \cdot 2$ & $0 \cdot 04 \dagger$ \\
\hline Free testosterone $(\mathrm{pg} / \mathrm{ml})$ & $11 \cdot 1 \pm 1 \cdot 5$ & $9 \cdot 8 \pm 0 \cdot 5$ & ns \\
\hline Luteinizing hormone $(\mathrm{mlU} / \mathrm{ml})$ & $3 \cdot 2 \pm 0 \cdot 7$ & $6 \cdot 1 \pm 0 \cdot 8$ & $0 \cdot 02^{*}$ \\
\hline Follicle-stimulating hormone $(\mathrm{mlU} / \mathrm{ml})$ & $6 \cdot 5 \pm 1$ & $9 \cdot 7 \pm 1 \cdot 6$ & ns \\
\hline Prolactin $(\mathrm{mlU} / \mathrm{ml})$ & $194 \pm 21$ & $211 \pm 16$ & ns \\
\hline
\end{tabular}

Results are expressed as means \pm S.E.M. * Mann-Whitney $U$ test. $†$ Student's $t$ test. NM, not measured; $\mathrm{ns}$, not statistically significant.

previous studies have indicated that gender-associated differences in susceptibility to autoimmune diseases may be related to sex differences in cytokine secretion by circulating immunocompetent cells (Bebo et al. 1999, Liva \& Voskuhl 2001).

Here we report a prospective study on the short- and long-term effects of androgen-replacement therapy on the circulating inflammatory cellular compartment of the immune system in a group of type- 2 diabetic men with partial androgen deficiency followed over 1 year of treatment.

\section{Materials and Methods}

\section{Patients and control subjects}

A total of 13 consecutive men older than 55 years (range, 55-73 years; mean \pm S.E.M. $64 \pm 2$ years) with type- 2 diabetes were enrolled in the study. Diagnosis of diabetes was established either from the patient's history or according to the American Diabetes Association criteria (American Diabetes Association 1998) in the case of patients with recent onset of diabetes. Type-2 diabetes was diagnosed on the basis of a history of initial successful treatment with oral hypoglycemic agents as well as by assessment of residual $\beta$-cell function, measuring $C$-peptide serum values. At the moment of entering the study the duration of diabetes ranged between 2 and 22 years. Four patients were treated with insulin, five with insulin plus oral hypoglycemic agents, and four with oral hypoglycemic agents. None of the patients had clinically evident atherosclerotic complications and all were ambulatory.

Inclusion criteria were: (1) a positive history of fertility (indicating previous testicular health); (2) a healthy partner (to prevent answers on the questionnaire used to obtain the clinical criteria of andropause from being influenced by exogenous factors); (3) absence of clinically overt hypogonadism, or hepatic, cardiac or renal insufficiency and (4) lack of ingestion of drugs that could induce hypogonadism. Exclusion criteria included diseases in which treatment with testosterone should be contraindicated, such as prostate cancer, active benign prostatic hyperplasia, breast carcinoma, sleep apnea, or chronic lung disease.

In addition to diabetic patients, eight healthy men with neither diabetes mellitus nor any of the components of the metabolic syndrome, of similar age (range, 52-76 years; mean \pm s.E.M. $64 \pm 3$ years), weight and body mass index to the diabetic patients, were studied in parallel as a control group (Table 1). Control individuals were recruited in the same outpatient clinic as the diabetic patients. The patients and controls did not have infection, inflammatory or allergic diseases nor were they receiving treatment with glucocorticoids or nonsteroidal antiinflammatory drugs, and they all gave written informed consent prior to entering the study. The study protocol was approved by the local research ethics committee of the University Hospital of Salamanca, Spain.

\section{Clinical and hormonal criteria of partial androgen deficiency}

Clinical criteria to define partial androgen deficiency were established on the basis of a specific questionnaire consisting of eight items related to androgen deficiency, which has been previously described in detail (Corrales et al. 2004). This questionnaire had a sensitivity of $90 \%$ and a specificity of $74 \%$ when applied to aging type-2 diabetic patients (Corrales et al. 2003). The questionnaire was applied by the same person in all but one case and all patients had positive questionnaires and hence met the clinical criteria of androgen deficiency. 
Androgen deficiency was confirmed using a biochemical criterion consisting of a total testosterone serum level of $\leq 3 \cdot 4 \mathrm{ng} / \mathrm{ml}$, according to its normal concentrations in a group of healthy young fertile controls (Corrales et al. 2000). This figure is similar or identical to the level used to define biochemical andropause by authorities in the field (Kaufman \& Vermeulen 1997) or in recent epidemiological studies (Harman et al. 2001). In a few patients who met the clinical criteria for androgen deficiency but displayed total serum testosterone values marginally higher than $3.4 \mathrm{ng} / \mathrm{ml}$, the criterion of free testosterone values of $\leq 11 \mathrm{pg} / \mathrm{ml}$, which represent the lower end of the normal range in young adults, was used. In agreement with our recommendations (Nieschlag et al. 2004) symptoms were always considered in the context of the full clinical picture in relation to testosterone serum levels; thus partial androgen deficiency was considered when a patient met both the clinical and biochemical criteria defined above.

\section{Hormone and other laboratory measurements}

Blood samples were obtained for all laboratory measurements simultaneously between 8:00 to 9:00 AM. Plasma glucose levels were assayed by a glucose oxidase method. Total and free testosterone concentrations were measured by solid-phase $\left[{ }^{125}\right.$ I]RIA (Coat-a-Count; DPL, Los Angeles, CA, USA) and luteinizing hormone (LH), follicle-simulating hormone (FSH), and prolactin levels were determined with a RIA (RIA-gnost; CIS Bio International, Gif-sur-Yvette, France), as previously described in detail (García-Díez et al. 1983, Corrales et al. 2000). The RIA-React (CIS Bio International) and the INS-Irma (Biosource, Nivelles, Belgium) RIAs were used to measure prostate-specific antigen (PSA) and insulin serum levels, respectively. C-peptide levels were determined using a commercial RIA (C-PEP; Biosource). $\mathrm{HbA}_{1} \mathrm{c}$ (Menarini Diagnostics, Florence, Italy) and fructosamine (Fruc; Roche Diagnostics) were measured using commercial kits.

The sensitivities and the intra- and interassay coefficients of variation of the methods were: $0 \cdot 04 \mathrm{ng} / \mathrm{ml}, 5 \cdot 7 \%$ and $6.7 \%$, respectively, for total testosterone; $0 \cdot 15 \mathrm{pg} / \mathrm{ml}$, $5.4 \%$ and $8.5 \%$ for free testosterone; $0 \cdot 1 \mathrm{mIU} / \mathrm{ml}, 2 \cdot 9 \%$ and $3 \%$ for $\mathrm{LH} ; 0 \cdot 1 \mathrm{mIU} / \mathrm{ml}, 3 \cdot 4 \%$ and $3 \%$ for $\mathrm{FSH}$; $2 \mu \mathrm{IU} / \mathrm{ml}, 6 \cdot 9 \%$ and $7 \cdot 8 \%$ for prolactin; $0.04 \mathrm{ng} / \mathrm{ml}, 2 \cdot 2 \%$ and $4.2 \%$ for PSA; $1.5 \mu \mathrm{IU} / \mathrm{ml}, 6.9 \%$ and $8.1 \%$ for insulin; $0.04 \mathrm{pmol} / \mathrm{ml}, 8 \cdot 2 \%$ and $9 \cdot 3 \%$ for C-peptide; $2 \cdot 5 \%, 5 \cdot 2 \%$, and $5 \cdot 2 \%$ for $\mathrm{HbA}_{1} \mathrm{c} ; 10 \mu \mathrm{mol} / 1,0.9 \%$ and $2 \cdot 9 \%$ for fructosamine.

\section{Treatment with testosterone}

Diabetic patients meeting the criteria of androgen deficiency were treated with $150 \mathrm{mg}$ intramuscular testosterone enanthate every 15 days for 1 year. They were studied prior to therapy, and at months 1, 3, 6 and 12 of testosterone therapy. On each of these visits, the following laboratory safety tests were performed: complete blood count, blood pressure, PSA levels and liver tests; in addition, symptoms of urinary obstruction were also evaluated. During follow-up, measurements of total and free testosterone levels were performed on day 8 after each injection. Evaluation of treatment compliance was performed by monitoring the decrease in serum LH levels induced by exogenously added testosterone.

\section{Identification and enumeration of peripheral blood $(P B)$ monocyte, dendritic cell (DC) and lymphocyte subsets}

Identification and enumeration of PB monocytes, DCs and lymphocytes were performed on EDTAanticoagulated PB samples stained with specific combinations of monoclonal antibodies (mAbs) using a direct immunofluorescence, single-platform flow cytometry technique as previously described (Almeida et al. 2001). Briefly, $100 \mu \mathrm{l}$ of a pre-mixed PB sample was placed in two separate tubes and stained for $15 \mathrm{~min}$ at room temperature (RT) with the Dendritic Cell Exclusion kit, which contains a mixture of FITC-conjugated antiCD3, CD14, CD19 and CD56 mAbs (Cytognos, Salamanca, Spain), CD16-phycoerythrin (PE; clone 3 G8; Immunotech, Marseille, France), anti-HLA-DR-peridin in chlorophyll protein (PerCP; clone L243; Becton Dickinson Biosciences, San Jose, CA, USA) and CD33allophycocyanin (clone LeuM9; Becton Dickinson Biosciences) $\mathrm{mAb}$ or the LYMPHOGRAM reagent (Cytognos). Then cells were incubated with $2 \mathrm{ml}$ of either Quicklysis (Cytognos) or FACS lysing solution (Becton Dickinson Biosciences) for $10 \mathrm{~min}$ at RT. Once this incubation period was finished, the cells stained with the LYMPHOGRAM reagent were centrifuged at $540 \mathrm{~g}$ ( 5 min, RT); following this, the lysing solution was removed, and the cell pellet washed twice in $2 \mathrm{ml}$ PBS $(\mathrm{pH} 7 \cdot 6)$ and resuspended in $0.5 \mathrm{ml}$ PBS. Immediately prior to data acquisition, $100 \mu \mathrm{l}$ pre-mixed Perfect-Count beads (Cytognos) were added to the other tube. After gentle mixing samples were run on a FACSCalibur flow cytometer (Becton Dickinson Biosciences) using CellQUEST software (Becton Dickinson Biosciences). Data acquisition was performed as previously described, collecting information on $>10^{3}$ DCs (defined as those cells being of the ${\mathrm{MHC}-\mathrm{II}^{+} / \text {lineage }}^{-/ \mathrm{dim}^{+}}$) and $>10^{4}$ lymphocytes. For data analysis, Paint-A-Gate Pro software (Becton Dickinson Biosciences) was used.

In addition to the monocytes, the following subsets of DCs and lymphocytes were identified: (1) myeloid DCs $\left(\mathrm{CD} 33^{\mathrm{hi}}\right)$; (2) CD16+ DCs $\left(\mathrm{CD} 33+, \mathrm{CD} 14^{-/ \mathrm{dim}+}\right)$; (3) plasmacytoid DCs $\left(\mathrm{CD} 33^{-/ \mathrm{dim}+}\right.$; Almeida et al. 1999, 2001); (4) CD4+/CD8 - T cells; (5) CD8+/CD4 - T lymphocytes; (6) CD4 - /CD8 - T cells; (7) CD4+/ CD8+ T lymphocytes; (8) CD4-/CD8+dim T-cells; 
(9) $\mathrm{CD} 4+/ \mathrm{CD}^{\mathrm{dim}+} \mathrm{T}$ cells; (10) CD56+/CD8+ natural killer (NK) cells; (11) CD56+/CD8 - NK cells and (12) CD19+ B lymphocytes.

\section{Analysis of cytokine secretion by PB monocytes and DCs}

The spontaneous and stimulated secretion of cytokines by monocytes and DCs was analyzed at the single-cell level in heparinized PB samples, using a well-established fourcolor staining technique that combines the specific identification of monocytes and DCs with the measurement of intracellular cytokine production after short-term in vitro culture (Almeida et al. 1999, Bueno et al. 2001). Briefly, $500 \mu \mathrm{l}$ heparin-anticoagulated PB was placed in a tube, to which $100 \mathrm{ng} / \mathrm{ml}$ lipopolysaccharide (LPS; from Escherichia coli serotype 055:B5; Sigma) and $10 \mathrm{ng} / \mathrm{ml}$ human recombinant interferon $\gamma$ (IFN $\gamma$; Promega) were added for the specific stimulation of $\mathrm{PB}$ MHC-II ${ }^{+}$/ lineage ${ }^{-}$cells (Bueno et al. 2001). Then, $500 \mu \mathrm{l}$ RPMI 1640 culture medium (BioWhittaker, Walkersville, MD, USA) supplemented with $2 \mathrm{mM}$ L-glutamine was added to complete a final volume of $1 \mathrm{ml}$. In addition, $10 \mu \mathrm{g} / \mathrm{ml}$ brefeldin A (Sigma; Bueno et al. 2001) was added to block cytokine secretion by cytokine-producing cells. An unstimulated sample also containing brefeldin $\mathrm{A}$ and processed in an identical way in the absence of any exogenous stimuli was used to evaluate spontaneous ex vivo cytokine secretion. Then cells were incubated for $6 \mathrm{~h}$ at $37{ }^{\circ} \mathrm{C}$ in a $5 \% \mathrm{CO}_{2}$ and $95 \%$ humidity sterile environment, as previously described in detail (Almeida et al. 1999). Once this incubation period had ended, the sample was aliquoted into four different tubes (approximately $200 \mu \mathrm{l} /$ tube) and cells were stained with the Dendritic Cell Exclusion kit, anti-HLA-DR-PerCP and CD33-allophycocyanin. After a gentle mixing, cells were incubated for $15 \mathrm{~min}$ in the darkness (at RT), washed in $2 \mathrm{ml}$ PBS, fixed, permeabilized and stained with $\mathrm{mAbs}$ directed against different human inflammatory cytokines using the Fix \& Perm reagent kit (Caltag, San Francisco, CA, USA) according to the recommendations of the manufacturer. The $\mathrm{mAb}$ reagents used to detect intracellular cytokines were as follows: anti-interleukin (IL)-6-PE (clone MQ2-6A3; Pharmingen, San Diego, CA, USA); anti-tumor necrosis factor $\alpha$ (TNF $\alpha$ )-PE (clone 11; Pharmingen) and anti-IL-1 $\beta$-PE (clone AS10; Becton Dickinson Biosciences). Isotype-matched negative $\mathrm{mAb}$ reagents conjugated with $\mathrm{PE}$ were used as negative controls.

Data acquisition and analysis were performed on a FACSCalibur flow cytometer as described above. For data analysis, cytokine production by specific subsets of DCs and monocytes was calculated in terms of both the percentage of positive cells within each cell subset and the mean fluorescence intensity (MFI) obtained for each specific cytokine after subtracting the MFI of the corresponding isotype-matched negative control.

\section{Statistical analyses}

Data were analyzed using SPSS software (SPSS 12.0; Chicago, IL, USA). The normal quantile (Normal Q-Q Plot) test was used to assess whether or not data for each variable had a normal distribution. The statistical significance of the differences observed between healthy controls and diabetic men (unpaired samples) was determined using the Student's $t$ and Mann-Whitney $U$ tests for variables with a normal and non-parametric distribution, respectively. The statistical significance of the differences observed between distinct treatment time points in diabetic samples (paired samples) was determined using the non-parametric Friedman and Wilcoxon signed-rank tests. The relationship between plasma hormone values (testosterone, $\mathrm{LH}$ and $\mathrm{FSH}$ ) with antigen-presenting cell (APC) counts (monocytes and DCs) was tested by Spearman correlation analysis. $P$ values (two-tailed) of $\leq 0.05$ were considered to be associated with statistical significance.

\section{Results}

The clinical characteristics of the control subjects and type-2 diabetic men are shown in Table 1. Both groups had similar anthropometric features but, as expected, exhibited significantly different fasting plasma glucose $(P=0.001)$ and $\mathrm{C}$-peptide $(P=0.04)$ levels. In addition, the diabetic patients had lower serum concentrations of total testosterone $(P=0.04)$ and higher LH levels $(P=0.02)$ than controls. Replacement therapy with testosterone enanthate increased the serum levels of total and free testosterone while the serum values of $\mathrm{LH}$ decreased to undetectable levels (Fig. 1).

All but one patient completed the 12-month course of testosterone-replacement therapy. During this period, no patient had any adverse cardiovascular or prostatic events. In one patient, testosterone therapy was withdrawn after completing 6 months of treatment due to an increase in his hematocrit value above $52 \%$. In another two cases, a phlebotomy was performed at 6 and 9 months after starting treatment because of a hematocrit value of between 50 and $52 \%$. The mean PSA levels before and after testosterone treatment were 1.4 and $1.8 \mathrm{ng} / \mathrm{ml}$, respectively. No significant differences in weight were detected before testosterone therapy or at the end of treatment (78 \pm 14 compared with $76 \pm 14 \mathrm{~kg}$, respectively).

Prior to testosterone-replacement therapy, the type-2 diabetic men showed higher white blood cell $(P \leq 0 \cdot 05)$ and monocyte $(\mathrm{p} \leq 0 \cdot 05)$ counts, together with increased numbers of CD $4-/ \mathrm{CD} 8^{\text {lo }} \mathrm{T}$ cells $(P \leq 0 \cdot 01)$ as compared with the control subjects (Table 2 ). In general, testosterone treatment did not induce significant quantitative changes in most of the subsets of white blood cells studied, in either absolute or relative numbers, which remained stable and similar to those found before treatment. 


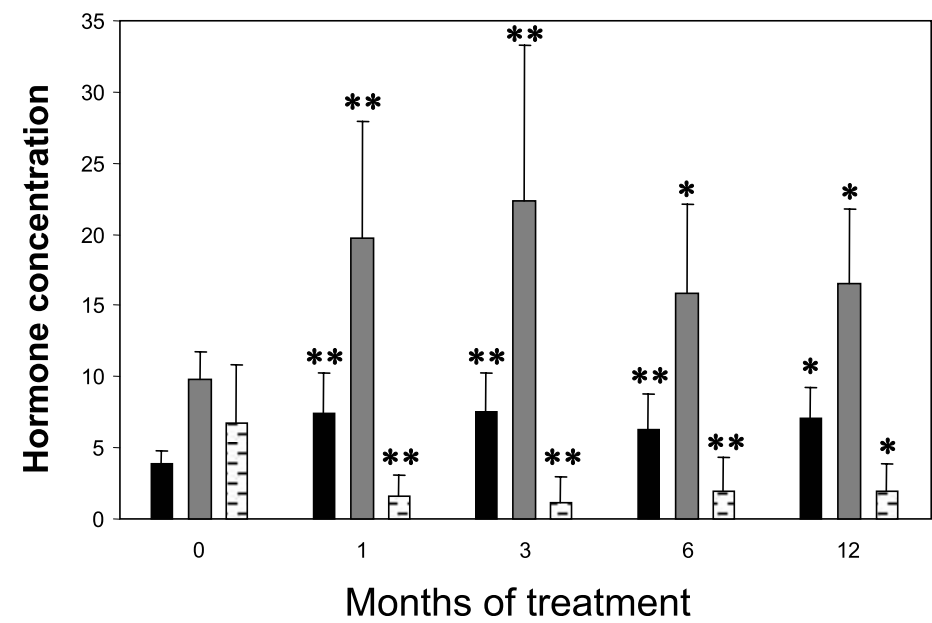

Figure 1 Serum concentrations of testosterone and LH before (0) and during 12 months of treatment with $150 \mathrm{mg}$ testosterone enanthate administered intramuscularly in 13 type- 2 diabetic men. Results are expressed as means \pm S.D. ${ }^{*} P<0 \cdot 05$, vs before treatment; ${ }^{*} P<0 \cdot 01$ vs before treatment. $\Pi$, total testosterone; $\mathrm{FT}$, free testosterone.

Despite this, some exceptions were noted, including a transient increase in the number of polymorphonuclear leukocytes at month 1 of treatment $(P<0 \cdot 05)$, as well as both an increase in the number of CD $4-/ \mathrm{CD} 8+\mathrm{T}$ cells $(P<0 \cdot 05)$ and a decrease in the proportion of CD4+/
CD8 $-\mathrm{T}$ cells $(P<0 \cdot 05)$ at the end of therapy $(6$ and 12 months); these were associated with a transient increase in the percentage of CD56+/CD8 - NK cells (1 month of therapy) and a decrease in the percentage of CD56+ $/$ CD8+ NK cells (at 1 month), with respect to the data

Table 2 Distribution of monocytes and subsets of lymphocytes and dendritic cells (DCs) in PB samples from type-2 diabetic men with partial androgen deficiency prior to and during testosterone-replacement therapy (TX), as compared to healthy age-matched controls

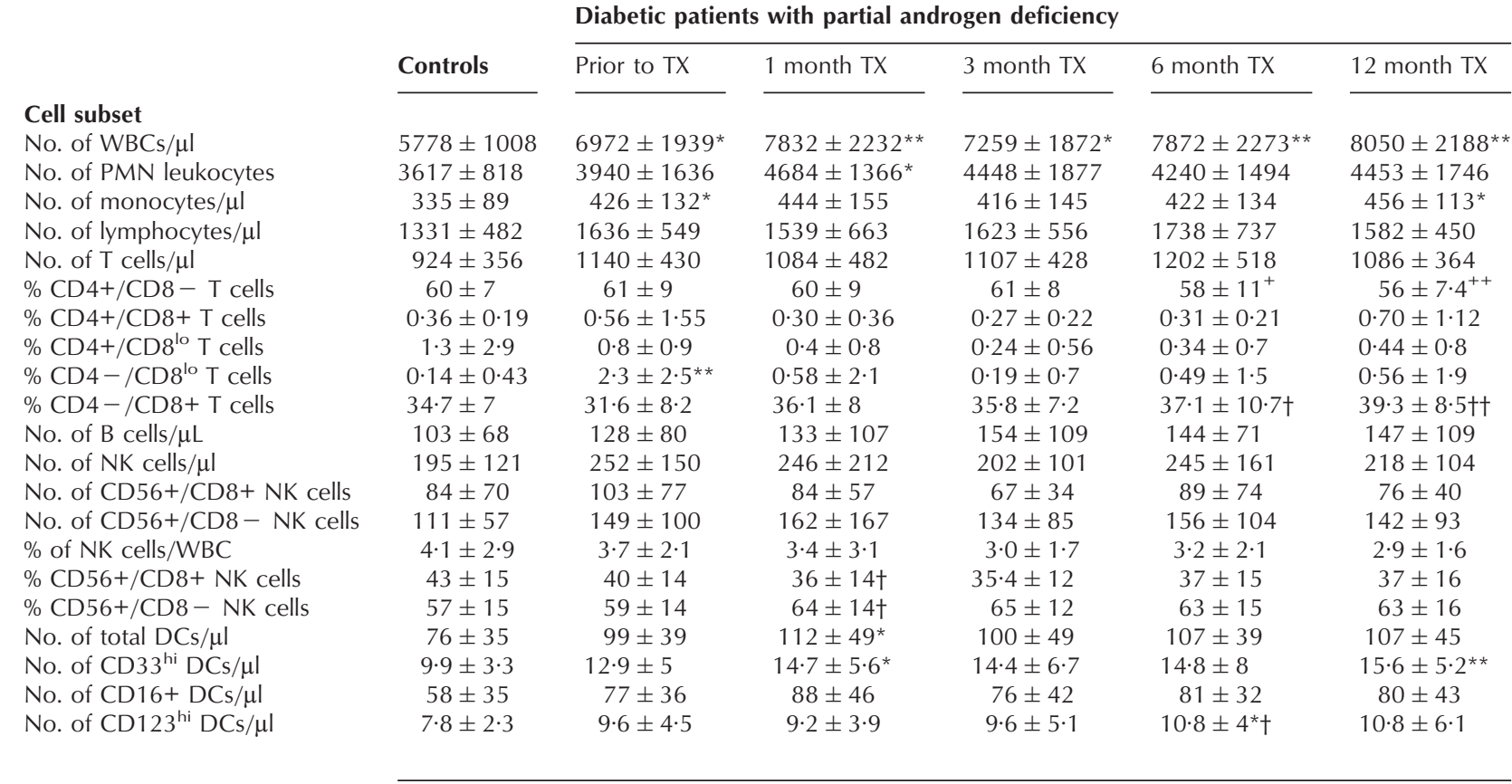

Results are expressed as means \pm S.D. Statistical analyses were performed using the Mann-Withney $U$ test (for comparisons between healthy controls and diabetic men) and both the Friedman and Wilcoxon signed rank tests (for comparisons between distinct treatment time-points in diabetic samples). ${ }^{*} \leqslant 0 \cdot 05$ and ${ }^{* *} P \leqslant 0 \cdot 01$ vs controls; $\dagger P<0 \cdot 05$ and $+\dagger P<0 \cdot 01$ vs prior to TX. WBC, white blood cells; Nk, natural killer cells; PMN, polymorphonuclear. 
Table 3 Spontaneous ex vivo secretion of inflammatory cytokines by peripheral blood monocytes and dendritic cells (DCs) in type-2 diabetic patients with partial androgen deficiency before treatment and after 1, 3, 6 and 12 months of testosterone-replacement therapy (TX), in comparison to control subjects

\section{Type-2 diabetic men}

\begin{tabular}{|c|c|c|c|c|c|c|}
\hline & \multirow[b]{2}{*}{ Controls } & \multirow[b]{2}{*}{ Prior to treatment } & \multirow[b]{2}{*}{1 month TX } & \multirow[b]{2}{*}{3 month TX } & \multirow[b]{2}{*}{6 month TX } & \multirow[b]{2}{*}{12 month TX } \\
\hline & & & & & & \\
\hline$\%$ of IL- $1 \beta$ & $0 \cdot 8 \pm 1 \cdot 6$ & $0 \cdot 3 \pm 1 \cdot 1$ & $<0.01$ & $<0 \cdot 01$ & $<0 \cdot 01$ & $<0 \cdot 01$ \\
\hline$\%$ of IL- 6 & $3 \cdot 0 \pm 4 \cdot 3$ & $2 \cdot 5 \pm 8 \cdot 1$ & $1 \cdot 6 \pm 1 \cdot 8$ & $2 \cdot 8 \pm 3 \cdot 3$ & $4 \cdot 1 \pm 4 \cdot 9$ & $<0 \cdot 01^{*}$ \\
\hline MFI of IL- 6 & $275 \pm 132$ & $292 \pm 168$ & $232 \pm 169$ & $315 \pm 288$ & $160 \pm 76$ & NE \\
\hline$\%$ of TNF $\alpha$ & $3 \cdot 1 \pm 4 \cdot 8$ & $2 \cdot 3 \pm 4 \cdot 5$ & $1 \cdot 7 \pm 2 \cdot 3$ & $3 \cdot 1 \pm 5 \cdot 6$ & $1 \cdot 5 \pm 2 \cdot 4$ & $<0 \cdot 01 \dagger^{*}$ \\
\hline$\%$ of IL- $1 \beta$ & $<0 \cdot 01$ & $<0 \cdot 01$ & $<0.01$ & $<0 \cdot 01$ & $<0 \cdot 01$ & $<0 \cdot 01$ \\
\hline MFI of IL- $1 \beta$ & NE & NE & NE & NE & NE & NE \\
\hline$\%$ of IL- 6 & $<0 \cdot 01$ & $0 \cdot 6 \pm 2 \cdot 3$ & $<0 \cdot 01$ & $2 \cdot 1 \pm 5$ & $<0 \cdot 01$ & $<0 \cdot 01$ \\
\hline MFI of IL-6 & NE & $453 \pm 340$ & NE & $232 \pm 81$ & NE & NE \\
\hline$\%$ of TNF $\alpha$ & $<0 \cdot 01$ & $1 \cdot 4 \pm 4$ & $2 \cdot 6 \pm 6 \cdot 6$ & $1 \cdot 1 \pm 2 \cdot 8$ & $<0 \cdot 01$ & $<0 \cdot 01$ \\
\hline MFI of TNF $\alpha$ & NE & $653 \pm 406$ & $319 \pm 3854$ & $446 \pm 485$ & NE & NE \\
\hline MFI of IL-6 & $215 \pm 105$ & $249 \pm 152$ & $196 \pm 160$ & $202 \pm 117$ & $186 \pm 78$ & $161 \pm 23$ \\
\hline$\%$ of TNF $\alpha$ & $3 \cdot 1 \pm 5 \cdot 2$ & $2 \cdot 8 \pm 8 \cdot 2$ & $3 \cdot 7 \pm 4 \cdot 1$ & $9 \cdot 1 \pm 21 \cdot 8$ & $2 \cdot 6 \pm 4 \cdot 4$ & $1 \cdot 7 \pm 1 \cdot 4$ \\
\hline MFI of TNF $\alpha$ & $787 \pm 468$ & $568 \pm 398$ & $327 \pm 267$ & $556 \pm 689$ & $361 \pm 213$ & $203 \pm 59$ \\
\hline \multicolumn{7}{|c|}{ Plasmacytoid DCs } \\
\hline$\%$ of IL- $1 \beta$ & $<0 \cdot 01$ & $<0 \cdot 01$ & $<0.01$ & $<0 \cdot 01$ & $<0 \cdot 01$ & $<0 \cdot 01$ \\
\hline MFI of IL- $1 \beta$ & NE & NE & NE & NE & NE & NE \\
\hline$\%$ of IL- 6 & $10 \pm 20$ & $7 \cdot 6 \pm 13 \cdot 6$ & $9 \cdot 5 \pm 13 \cdot 4$ & $12 \cdot 4 \pm 17$ & $<0.01$ & $<0.01$ \\
\hline MFI of IL-6 & $49 \pm 8$ & $69 \pm 19$ & $53 \pm 8$ & $56 \pm 9$ & NE & NE \\
\hline$\%$ of TNF $\alpha$ & $6 \cdot 8 \pm 10 \cdot 3$ & $6 \cdot 9 \pm 12 \cdot 6$ & $8 \cdot 6 \pm 11 \cdot 6$ & $4 \cdot 8 \pm 9 \cdot 2$ & $3 \cdot 3 \pm 8 \cdot 9$ & $<0 \cdot 01$ \\
\hline $\mathrm{MFI}$ of $\mathrm{TNF} \alpha$ & $47 \pm 7$ & $57 \pm 13$ & $51 \pm 12$ & $60 \pm 14$ & $58 \pm 4$ & NE \\
\hline
\end{tabular}

Results are expressed as means \pm S.D. Statistical analyses were performed using the Mann-Witney $U$ test for comparisons between healthy controls and diabetic men and both the Friedman and Wilcoxon signed rank tests for comparisons between distinct treatment time points in diabetic samples. ${ }^{*} \leqslant 0 \cdot 05$ vs controls; $\uparrow P \leqslant 0.05$ vs prior to therapy. MFI, mean fluorescence intensity; NE, not evaluated owing to the absence of cytokine-positive cells.

before treatment. In addition, transient increases in the number of CD $33^{\text {hi }}$ myeloid DCs (months 1 and 12 of therapy) and CD123 hi plasmacytoid DCs (month 6) to values significantly higher than those of the controls were also observed during treatment with testosterone (Table 2).

Small percentages of monocytes and DCs capable of spontaneously secreting detectable amounts of proinflammatory cytokines were detected in both the diabetic men and the control group prior to therapy (Table 3). After testosterone-replacement therapy, the number of $\mathrm{PB}$ monocytes capable of spontaneously producing IL-1 $\beta$, IL-6 and TNF $\alpha$ became undetectable both at the first follow-up time point (IL-1 $\beta$ ) and at the end of therapy (IL-6 and TNF $\alpha$ ). Likewise, the percentage of CD33 ${ }^{\text {hi }}$ myeloid DCs and that of plasmacytoid DCs capable of spontaneously producing IL-6 and TNF $\alpha$ also became undetectable during testosterone treatment. In contrast, no major changes were observed with testosterone- replacement therapy in the spontaneous production of proinflammatory cytokines by peripheral blood CD16+ DCs (Table 3).

Prior to therapy, CD33 ${ }^{\text {hi }}$ myeloid DCs and CD16+ DCs from the diabetic men showed a decreased ability to secrete IL-1 $\beta(P \leq 0 \cdot 05)$ after in vitro stimulation with LPS as compared with the control group (Table 4). Testosterone-replacement therapy was associated with a transient recovery of the percentage of IL- $1 \beta$-secreting CD $33^{\text {hi }}$ myeloid DCs and CD16+ DCs at months 3 and 12 , and month 3 of therapy, respectively. In addition, testosterone-replacement therapy was also associated with a decreased number of TNF $\alpha$-secreting plasmacytoid DCs at month 12 .

Interestingly, analysis of the relationship between plasma hormone levels (testosterone, LH and FSH) and cytokine production by different subsets of PB APCs in diabetic men revealed a statistically significant negative correlation between the levels of $\mathrm{LH}$ and the percentage 
Table 4 In vitro-stimulated secretion of inflammatory cytokines by peripheral blood (PB) monocytes and dendritic cells (DCs) in type-2 diabetic patients with partial androgen deficiency before treatment and after 1, 3, 6 and 12 months of testosterone-replacement therapy (TX), in comparison to control subjects

\section{Type-2 diabetic men}

\begin{tabular}{|c|c|c|c|c|c|c|}
\hline & Controls & Before treatment & 1 month TX & 3 month TX & 6 month TX & 12 month TX \\
\hline \multicolumn{7}{|c|}{ Cells and cytokines } \\
\hline \multicolumn{7}{|c|}{ Monocytes } \\
\hline$\%$ of IL-1 $\beta$ & $100 \pm 0$ & $90 \pm 25$ & $84 \pm 27^{*}$ & $92 \pm 23 \dagger$ & $75 \pm 39$ & $93 \pm 21$ \\
\hline$\%$ of IL-6 & $96 \pm 11$ & $89 \pm 26$ & $91 \pm 22$ & $83 \pm 31$ & $76 \pm 34$ & $86 \pm 28$ \\
\hline MFI of IL- 6 & $2407 \pm 1575$ & $2176 \pm 1486$ & $1838 \pm 1008$ & $2224 \pm 1433$ & $1124 \pm 942$ & $1356 \pm 898$ \\
\hline$\%$ of TNF $\alpha$ & $87 \pm 26$ & $88 \pm 29$ & $87 \pm 23$ & $93 \pm 18$ & $79 \pm 30$ & $84 \pm 29$ \\
\hline$\%$ of IL-1 $\beta$ & $96 \pm 12$ & $86 \pm 20^{*}$ & $80 \pm 22^{*}$ & $93 \pm 10 \dagger$ & $78 \pm 23^{*}$ & $95 \pm 9 \dagger$ \\
\hline MFI of IL-1 $\beta$ & $50 \pm 25$ & $60 \pm 43$ & $56 \pm 40$ & $46 \pm 15$ & $41 \pm 12$ & $42 \pm 14$ \\
\hline$\%$ of IL-6 & $89 \pm 24$ & $90 \pm 18$ & $90 \pm 17$ & $90 \pm 20$ & $83 \pm 23$ & $92 \pm 14$ \\
\hline MFI of IL-6 & $957 \pm 755$ & $911 \pm 674$ & $729 \pm 359$ & $831 \pm 572$ & $388 \pm 284$ & $537 \pm 361$ \\
\hline$\%$ of TNF $\alpha$ & $92 \pm 16$ & $80 \pm 28$ & $83 \pm 23$ & $90 \pm 20$ & $86 \pm 18$ & $89 \pm 21$ \\
\hline MFI of TNF $\alpha$ & $979 \pm 641$ & $1349 \pm 950$ & $1251 \pm 1010$ & $1098 \pm 601$ & $612 \pm 484$ & $726 \pm 608$ \\
\hline MFI of IL-6 & $2049 \pm 1255$ & $1685 \pm 1190$ & $1354 \pm 868$ & $1672 \pm 1047$ & $915 \pm 563^{*}$ & $1092 \pm 742$ \\
\hline$\%$ of TNF $\alpha$ & $89 \pm 22$ & $86 \pm 26$ & $84 \pm 26$ & $92 \pm 20$ & $82 \pm 25$ & $85 \pm 28$ \\
\hline MFI of TNF $\alpha$ & $3961 \pm 2055$ & $3215 \pm 2002$ & $2866 \pm 1742$ & $3333 \pm 1559$ & $1780 \pm 1320^{* *}$ & $2478 \pm 1567$ \\
\hline \multicolumn{7}{|c|}{ Plasmacytoid DCsł } \\
\hline$\%$ of IL-6 & $17 \pm 19$ & $9 \pm 18$ & $22 \pm 21$ & $17 \pm 19$ & $9 \pm 16$ & $12 \pm 21$ \\
\hline MFI of IL-6 & $60 \pm 12$ & $79 \pm 23$ & $62 \pm 9$ & $70 \pm 14$ & $57 \pm 7$ & $56 \pm 6$ \\
\hline$\%$ of TNF $\alpha$ & $14 \pm 19$ & $11 \pm 19$ & $18 \pm 16$ & $15 \pm 19$ & $8 \pm 20$ & $4 \pm 13 \dagger$ \\
\hline MFI of TNF $\alpha$ & $62 \pm 13$ & $67 \pm 15$ & $54 \pm 10$ & $64 \pm 13$ & $53 \pm 2$ & $<0 \cdot 01$ \\
\hline
\end{tabular}

Results are expressed as means \pm S.D. Statistical analyses were performed using the Mann-Witney $U$ test for comparisons between healthy controls and diabetic men and both the Friedman and Wilcoxon signed rank tests for comparisons between distinct treatment time points in diabetic samples. ${ }^{\star} P \leqslant 0 \cdot 05$ and ${ }^{* *} P \leqslant 0 \cdot 01$ versus controls. $+P \leqslant 0 \cdot 05$ and $+\dagger P \leqslant 0 \cdot 01$ versus before treatment. $¥$ No plasmacytoid DCs capable of producing IL-1 $\beta$ were detected in either controls or diabetics. MFI, mean fluorescence intensity.

of both monocytes $\left(r^{2}=-0 \cdot 329 ; P=0 \cdot 02\right)$ and CD16+ DCs $\left(r^{2}=-0 \cdot 311 ; P=0 \cdot 03\right)$ spontaneously producing IL-6 in untreated patients. In turn, LH serum levels correlated positively with both the mean amount of IL-6 spontaneously secreted per cell (MFI) by CD16 + DCs $\left(r^{2}=0.40 ; P=0.03\right)$ in both untreated and treated diabetic men and the mean amount of IL- 6 produced by CD $33^{\text {hi }}$ myeloid DCs after stimulation with LPS plus IFN $\gamma$ $\left(r^{2}=0 \cdot 419 ; P=0 \cdot 01\right)$ in type- 2 diabetic men during treatment with testosterone.

\section{Discussion}

In the present study we show for the first time that testosterone-replacement therapy in type- 2 diabetic men with partial androgen deficiency is associated with an almost complete abrogation of spontaneous ex vivo secretion of the IL- $\beta$, IL- 6 and TNF $\alpha$ inflammatory cytokines by both circulating PB monocytes and DCs. Interestingly, similar effects were observed for the various subsets of circulating APCs and the different inflammatory cytokines analyzed.

To date, few reports have analyzed the effects of androgen-replacement therapy on cytokine production in hypogonadal subjects. In this regard, it has been shown that androgen therapy in patients with Klinefelter's syndrome decreased the levels of serum IgA, IgG, IgM, IL-2 and IL-4 (Koçar et al. 2000). Likewise, testosteronereplacement therapy in hypogonadal men has been shown to induce reductions in TNF $\alpha$ and IL-1 $\beta$ serum levels, together with increased IL-10, in the absence of significant changes in the serum concentrations of IL-6 (Malkin et al. 2004). In turn, gonadotropin treatment in patients with idiopathic hypogonadotropic hypogonadism, significantly decreased the production of IL-1 $\beta$ and TNF $\alpha$ by stimulated PB mononuclear cells; this effect was associated with decreased serum levels of IL-2 and IL-4 and reduced PB counts of total lymphocytes, CD3+ and CD4+ $\mathrm{T}$ cells, CD19+ $\mathrm{B}$ cells and the $\mathrm{CD} 4+/ \mathrm{CD} 8+$ ratio (Yesilova et al. 2000, Musabak et al. 2003). In addition, it has been shown that acute hypogonadism induced in 
normal elderly men by administration of gonadotropinreleasing hormone $(\mathrm{GnRH})$ has the opposite effect, increasing the circulating levels of TNF $\alpha$ and IL-6. In turn, in these subjects subsequent transdermal testosterone therapy reduced the concentrations of TNF $\alpha$ but not those of IL-6 (Kosla et al. 2002). Our results confirm and expand these observations in that they show, in another model of human androgen deficiency, that androgenreplacement therapy depresses spontaneous ex vivo production of inflammatory cytokines by PB APCs. Interestingly, our results also indicate that depression of the production of proinflammatory cytokine associated with androgen therapy is not due to an exhaustion of the ability of these cells to produce these cytokines in diabetic men since stimulation of PB monocytes and DCs with LPS plus IFN $\gamma$ induced fairly similar patterns of response to those observed in a group of age-matched healthy controls.

Little is known about the effects of androgen treatment on DC in humans. In this sense, Galasso et al. (1996) investigated the effects of topical application of testosterone propionate on the epidermal density of CD1+ DCs in a group of women, detecting a clear reduction of these cells. Likewise, in the mouse, systemic and topical application of testosterone significantly reduced the density of epidermal Langerhans cells (Koyama et al. 1989).

In our patients, testosterone-replacement therapy could induce immunosuppressive effects through either direct or indirect mechanisms. Androgen receptors or their mRNA have been detected in both CD4+ and CD8+ T cells as well as in macrophages (Liva \& Voskuhl 2001, Tanriverdi et al. 2003) and it has been shown that testosterone may directly induce cytokine gene expression on CD4+ T lymphocytes via androgen receptors (Liva \& Voskuhl 2001). Monocyte-derived macrophages also express androgen receptors (McCrohon et al. 2000) and these cells may metabolize testosterone to $5 \alpha$-dihydrotestosterone (Araneo et al. 1991). In this regard, treatment of mice with flutamide, an androgen-receptor blocker, restores previously depressed cellular immunity after brain injury (Messingham et al. 2001). However, to the best of our knowledge no study has been reported so far in which the expression of androgen receptors is analyzed in DCs. Therefore, the key premise for a direct action of androgens on these cells is currently lacking. In turn, GnRH has immunostimulatory effects (Tanriverdi et al. 2003) and it has been suggested that the immunosuppressive effects of androgens could be indirectly mediated by $\mathrm{GnRH}$ (Jacobson \& Ansari 2004). Thus, whereas androgens have suppressive effects on $\mathrm{GnRH}$ and gonadotropin secretion, estrogens enhance their secretion through a positivefeedback effect (Jacobson \& Ansari 2004). In line with this notion, plasma levels of $\mathrm{LH}$ showed a significant correlation with IL-6 secretion by both CD16+ DCs and CD $33^{\text {hi }}$ myeloid DC in diabetic patients during treatment with testosterone. Another possibility could be related to the fact that the secretion of IL- $1 \beta$ and TNF $\alpha$ is under the positive influence of IFN $\gamma$, as also seen in this study, and it has been shown that the production of IFN $\gamma$ by immune cells is reduced by testosterone (Araneo et al. 1991).

The anti-inflammatory effects of androgen therapy observed in our model may have both beneficial and deleterious effects. Regarding the former, a depression in proinflammatory cytokine secretion induced by androgens in DC may in turn alter the patterns of cytokine secretion by $\mathrm{T}$ cells and alter their ability to direct T-helper responses (Cua \& Stohlman 1997, Chang et al. 2000). In this regard, it has been reported that sex steroids induce changes in cytokine secretion by APCs in mice (Wilcoxen et al. 2000); these changes polarize cytokine secretion by $\mathrm{T}$ cells towards a Th1 or Th2 pattern (Wilcoxen et al. 2000, Lanzavecchia \& Sallusto 2001). A decrease in the production of Th1-associated cytokines (IL-1 $\beta$, IL-6, IFN $\gamma$ and TNF $\alpha$ ) by immune cells may bias the balance towards a Th2 pattern (IL-4, IL-10, IL-12), which could protect subjects from autoimmune diseases (Dalal et al. 1997, Liva \& Voskuhl 2001), whereas a predominance of Th1 cytokines would enhance susceptibility to developing autoimmune disorders (Bao et al. 2002).

Since monocytes, DCs and the inflammatory cytokines they secrete play an important role in both the development of atheroma plaque and its stability (Hansson 2005) it could be speculated that a decrease in cytokine production might have anti-atheromatous effects. Therefore, the anti-inflammatory role of androgen-substitutive therapy in aging type-2 diabetic men with partial androgen deficiency, a condition associated with clinically evident atherosclerosis in humans (Fukui et al. 2003), could have atheroprotective effects (Malkin et al. 2003). In turn, a depressed immune response by APCs may be detrimental in terms of host defence. In this sense, it has been shown that females tolerate trauma hemorrhage and subsequent sepsis better than males (Schroder et al. 1998).

In summary, our findings indicate that androgenreplacement therapy in aging type-2 diabetic men with clinical and biochemical androgen deficiency has immunosuppressive and anti-inflammatory effects on both circulating PB monocytes and DCs. The anti-inflammatory effects of androgens may contribute to our understanding of the well-known relative resistance of males to autoimmune diseases and the outcome of atherosclerosis, and at the same time they could contribute to explain the depressive effect of androgens on host cellular immunity. Our results add new information to a promising field related to autoimmune diseases, gender responses to inflammation/sepsis, atheromatosis and plaque stability.

\section{Acknowledgements}

The authors declare that there is no conflict of interest that would prejudice the impartiality of this scientific work. 


\section{References}

Almeida J, Bueno C, Algueró MC, Sánchez ML, Cañizo MC, Fernández ME, Vaquero JM, Laso FJ, Escribano L, San Miguel JF et al. 1999 Extensive characterization of the immunophenotype and pattern of cytokine production by distinct subpopulations of normal human peripheral blood $\mathrm{MHCII}^{+} /$lineage $^{-}$cells. Clinical and Experimental Immunology 118 392-401.

Almeida J, Bueno C, Algueró MC, Sánchez ML, De Santiago M, Escribano L, Díaz-Agustín B, Vaquero JM, Laso FJ, San Miguel JM et al. 2001 Comparative analysis of the morphological, cytochemical, immunophenotypical, and functional characteristics of normal human peripheral blood lineage ${ }^{-} / \mathrm{CD}_{1} 6^{+} / \mathrm{HLA}_{-} \mathrm{DR}^{+} / \mathrm{CD} 14^{-/ \mathrm{lo}}$ cells, CD $14^{+}$monocytes, and $\mathrm{CD} 16^{-}$dendritic cells. Clinical Immunology 100 325-338.

American Diabetes Association 1998 The Expert Committee on the diagnosis and classification of Diabetes Mellitus. Report of the expert committee on the diagnosis and classification of diabetes mellitus. Diabetes Care 21 (suppl 1) S5-S19.

American Society for Reproductive Medicine 2004 The Practice Committee of the American Society for Reproductive Medicine. Treatment of androgen deficiency in the aging male. Fertility and Sterility 81 1437-1440.

Anderson B, Marin P, Lissner L, Vermeulen A \& Bjorntorp P 1994 Testosterone concentrations in women and men with NIDDM. Diabetes Care 17 405-411.

Araneo BA, Dowell T, Diegel M \& Daynes RA 1991. Dihydrotestosterone exerts a depressive influence on the production of interleukin-4 (IL-4), IL-5, and $\gamma$-interferon, but not IL-2 by activated murine T cells. Blood 78 688-699.

Bao M, Yang Y, Jun HS \& Yoon JW 2002. Molecular mechanisms for gender differences in susceptibility to $\mathrm{T}$ cell-mediated autoimmune diabetes in nonobese diabetic mice. Journal of Immunology 168 5369-5375.

Barrett-Connor E, Khaw KT \& Yen SSC 1990 Endogenous sex hormone levels in older adult men with diabetes mellitus. American Journal of Epidemiology 132 895-901.

Bebo BF Jr, Zelinka-Vincent E, Adamus G, Amundson D, Vandenbark AA \& Offner H 1998 Gonadal hormones influence the immune response to PLP 139-151 and the clinical course of relapsing experimental autoimmune encephalomyelitis. Journal of Neuroimmunology 84 122-130.

Bebo BF Jr, Schuster JC, Vandenbark AA \& Offner H 1999 Androgens alter the cytokine profile and reduce encephalitogenicity of myelin-reactive T cells. Journal of Immunology 162 35-40.

Bizzarro A, Valentini G, Di Martino G, Daponte A, De Bellis A \& Iacono G 1987 Influence of testosterone therapy on clinical and immunological features of autoimmune diseases associated with Klinefelter's syndrome. Journal of Clinical Endocrinology and Metabolism 64 32-36.

Bueno C, Almeida J, Algueró MC, Sánchez ML, Vaquero JM, Laso FJ, San Miguel JF, Escribano L \& Orfao A 2001 Flow cytometric analysis of cytokine production by normal human peripheral blood dendritic cells and monocytes: comparative analysis of different stimuli, secretion-blocking agents and incubation periods. Cytometry 46 33-40.

Chang CCJ, Wright A \& Punnonen J 2000 Monocyte-derived CD1a+ and CD1a- dendritic cell subsets differ in their cytokine production profiles, susceptibilities to transfection, and capacities to direct Th cell differentiation. Journal of Immunology $\mathbf{1 6 5}$ 3584-3591.

Corrales JJ, Burgo RM Miralles JM \& Villar E 2000 Abnormalities in sperm acid glycosidases from infertile men with idiopathic oligoasthenoteratozoospermia. Fertility and Sterility 73 470-478.

Corrales JJ, Burgo RM, Mories MT, Fraile A \& Miralles JM 2003 Andropausia en pacientes con diabetes mellitus de tipo 2. Análisis de criterios clínicos y bioquímicos para su identificación. Endocrinología y Nutrición 50 (suppl 2) 8-9.
Corrales JJ, Burgo RM, García-Berrocal B, Almeida M, Alberca I, González Buitrago JM, Orfao A \& Miralles JM 2004 Partial androgen deficiency in aging type 2 diabetic men and its relationship to glycemic control. Metabolism 53 666-672.

Cua DJ \& Stohlman SA 1997 In vivo effects of T helper cell type 2 cytokines on macrophage antigen-presenting cell induction of $\mathrm{T}$ helper subsets. Journal of Immunology 159 5834-5840.

Cutolo M, Sulli A, Capellino S, Villaggio B, Montagna P, Seriolo B \& Straub RH 2004 Sex hormones influence on the immune system: basic and clinical aspects in autoimmunity. Lupus 13 635-638.

Dalal M, Kim S \& Voskuhl RR 1997 Testosterone therapy ameliorates experimental autoimmune encephalomyelitis and induces a $\mathrm{T}$ helper 2 bias in the autoantigen-specific $\mathrm{T}$ lymphocyte response. Journal of Immunology 159 3-6.

Feldman HA, Longcope C, Derby CA, Johannes CB, Araujo AB, Coviello AD, Bremner WJ \& McKinlay JB 2002 Age trends in the level of serum testosterone and other hormones in middle-aged men: longitudinal results from the Massachusetts Male Aging Study. Journal of Clinical Endocrinology and Metabolism 87 589-598.

Fitzpatrick F, Lepault F, Homo-Delarche F, Bach JF \& Dardenne M 1991 Influence of castration, alone or combined with thymectomy, on the development of diabetes in nonobese diabetic mouse. Endocrinology 129 1382-1390.

Fukui M, Kitagawa Y, Nakamura N, Kadono M, Mogami S, Hirata C, Ichio N, Wada K, Hasegawa G \& Yoshikawa T 2003. Association between serum testosterone concentrations and carotid atherosclerosis in men with type 2 diabetes. Diabetes Care 26 1869-1873.

Galasso F, Altamura V \& Sbano E (1996). Effects of topical testosterone propionate on the positive nickel patch test. Journal of Dermatological Science 13 76-82.

García-Díez LC, González JM, Corrales JJ, Battaner E \& Miralles JM 1983 Hormone levels in serum and seminal plasma of men with different types of azoospermia. Journal of Reproduction and Fertility $67209-214$.

Gylling M, Kääriä inen E, Väisä nen R, Kerosuo L, Solin ML, Halme L, Saari S, Halonen M, Kämpe, Perheentupa J et al. 2003 The hypoparathyroidism of autoimmune PolyendocrinopathyCandidiasis-Ectodermal Dystrophy. Protective effect of male sex. Journal of Clinical Endocrinology and Metabolism 88 4602-4608.

Hajjar RR, Kaiser FE \& Morley JE 1997 Outcomes of long-term testosterone replacement in older hypogonadal males: a retrospective analysis. Journal of Clinical Endocrinology and Metabolism 82 3793-3796.

Hansson GK 2005 Inflammation, atherosclerosis, and coronary artery disease. New England Journal of Medicine 352 1685-1695.

Harman SM, Metter EJ, Tobin JD, Pearson J \& Blackman MR 2001 Longitudinal effects of aging on serum total and free testosterone levels in healthy men. Journal of Clinical Endocrinology and Metabolism 86 724-731.

Jacobson JD \& Ansari MA 2004 Immunomodulatory actions of gonadal steroids may be mediated by gonadotropin-releasing hormone. Endocrinology 145 330-336.

Janowsky JS, Oviatt SK \& Orwoll ES 1994 Testosterone influences spatial cognition in older men. Behavioral Neuroscience 108 325-332.

Kaufman JM \& Vermeulen A 1997 Declining gonadal function in elderly men. Baillière's Clinical Endocrinology and Metabolism 11 289-309.

Kenny AM, Prestwood KM, Gruman CA, Marcello KM \& Raisz LG 2001 Effects of transdermal testosterone on bone and muscle in older men with low bioavailable testosterone levels. Journals of Gerontology Biological Sciences and Medical Sciences 56 M266-M273.

Khosla S, Atkinson EJ, Dunstan CR \& O'Fallon WM 2002 Effect of estrogen vs testosterone on circulating osteoprotegerin and other cytokine levels in normal elderly men. Journal of Clinical Endocrinology and Metabolism 87 1550-1554. 
Koçar IH, Yesilova Z, Özata M, Turan M, Sengül A \& Özdemir IC 2000 The effect of testosterone replacement treatment on immunological features of patients with Klinefelter's syndrome. Clinical and Experimental Immunology 121 448-452.

Koyama Y, Nagao S, Ohashi K, Takahashi H \& Marunouchi T 1989 Effect of systemic and topical application of testosterone propionate on the density of epidermal Langerhans cells in the mouse. Journal of Investigative Dermatology 92 86-90.

Kunelius P, Lukkarinen O, Hannuksela MN, Itkonen O \& Tapanainen JS 2002 The effects of transdermal dihydrotestosterone in the aging male: A prospective, randomized, double blind study. Journal of Clinical Endocrinology and Metabolism 87 1467-1472.

Lanzavecchia A \& Sallusto F 2001 The instructive role of dendritic cells on T cell responses: lineages, plasticity and kinetics. Current Opinion in Immunology 13 291-298.

Liva SM \& Voskuhl RR 2001 Testosterone acts directly on CD4 ${ }^{+}$ $\mathrm{T}$ lymphocytes to increase IL-10 production. Journal of Immunology 167 2060-2067.

Malkin CJ, Pugh PJ, Jones RD, Jones TH \& Channer KS 2003 Testosterone as a protective factor against atherosclerosisimmunomodulation and influence upon plaque development and stability. Journal of Endocrinology 178 373-380.

Malkin CJ, Pugh PJ, Jones RD, Kapoor D, Channer RS \& Jones TH 2004 The effect of testosterone replacement on endogenous inflammatory cytokines and lipid profiles in hypogonadal men. Journal of Clinical Endocrinology and Metabolism 89 3313-3318.

McCrohon JA, Death AK, Nakhla S, Jessup W, Handelsman DJ, Stanley KK \& Celermajer DS 2000. Androgen receptor expression is greater in macrophages from male than from female donors. A sex difference with implications for atherosclerosis. Circulation $101224-226$.

Messingham KAN, Shirazi M, Duffner LA, Emanuele MA \& Kovacs EJ 2001. Testoterone receptor blockade restores cellular immunity in male mice after burn injury. Journal of Endocrinology 169 299-308.

Musabak U, Bolu E, Ozata M, Oktenli C, Sengul A, Inal A, Yesilova Z, Kilciler G, Ozdemir IC \& Koçar IH 2003 Gonadotropin treatment restores in vitro interleukin- $1 \beta$ and tumour necrosis factor- $\alpha$ production by stimulated peripheral blood mononuclear cells from patients with idiopathic hypogonadotropic hypogonadism. Clinical and Experimental Immunology 132 265-270.

Nieschlag E, Behre HM, Bouchard P, Corrales JJ, Jones TH, Stalla GK, Webb SM \& Wu FCW 2004 Testosterone replacement therapy: Current trends and future directions. Human Reproduction Update 10 409-419.

Schroder J, Kahlke V, Staubach KH, Zabel P \& Stuber F 1998 Gender differences in human sepsis. Archives of Surgery 133 1200-1205.

Sih R, Morley JE, Kaiser FE, Perry HM, Patrick P \& Ross C 1997 Testosterone replacement in older hypogonadal men: a 12-month randomized controlled trial. Journal of Clinical Endocrinology and Metabolism 82 1661-1667.

Snyder PJ, Peachey H, Hannoush P, Berlin JA, Loh L, Lenrow DA, Holmes JH, Dlewati A, Santanna J, Rosen CJ et al. 1999 Effect of testosterone treatment on body composition and muscle strength in men over 65 years of age. Journal of Clinical Endocrinology and Metabolism 84: 2647-2653.

Snyder PJ 2004 Hypogonadism in elderly men. What to do until the evidence comes. New England Journal of Medicine 350 440-442.

Tanriverdi F, Silveira LFG, MacColl GS \& Bouloux PMG 2003 The hypothalamic-pituitary-gonadal axis: immune function and autoimmunity. Journal of Endocrinology 176 293-304.

Tenover JS 1992 Effects of testosterone supplementation in the aging male. Journal of Clinical Endocrinology and Metabolism 75: 1092-1098.

Wilcoxen SC, Kirkman E, Dowdell KC \& Stohlman SA 2000 Gender-dependent IL-12 secretion by APC is regulated by IL-10. Journal of Immunology 164 6237-6243.

Yesilova Z, Ozata M, Koçar IH, Turam M, Pekel A, Sengul A \& Ozdemír IC 2000 The effects of gonadotropin treatment on the immunological features of male patients with idiopathic hypogonadotropic hypogonadism. Journal of Clinical Endocrinology and Metabolism 85 66-70.

Received in final form 8 March 2006

Accepted 16 March 2006

Made available online as an Accepted Preprint

22 March 2006 